\title{
On appraising alternative power plant investment proposals Part 1: the economic model
}

\author{
D Bohn ${ }^{1}$ and $\mathbf{J}$ E A Roy-Aikins*2 \\ ${ }^{1}$ Institute of Steam and Gas Turbines, Aachen University of Technology, Aachen, Germany \\ ${ }^{2}$ Department of Mechanical Engineering, University of Durban-Westville, Durban, South Africa
}

\begin{abstract}
Combined energy plants operating on the Brayton-Rankine cycle have gained wide acceptance as the most efficient energy conversion system. The technology is well proven and numerous research activities are underway to develop it further past its present plateau of performance. In developed and emerging economies alike, the current situation in the global economic market has caused the liberalization of the energy industry in some countries, and in others it is causing a rethink of economic and energy policies. A result is that electric utility companies that have enjoyed a monopoly in power generation and distribution are seeing this privilege being eroded. This is opening up opportunities for independent power production and, consequently, for gas/steam turbine plants because of the technical merits of the technology and its ability to fill the vacuum being created in the energy industry. An economic model has been developed for carrying out life cycle costs analysis of energy investment proposals involving gas and steam turbines in combined power and combined heat and power. A computer program for the economic analysis of combined energy systems (PEACES) was developed with a capability to evaluate the economic merits of individual and competing energy investment proposals. This paper describes the economic model around which the computer code was structured.
\end{abstract}

Keywords: combined energy systems, gas turbines, power plant economics, steam turbines

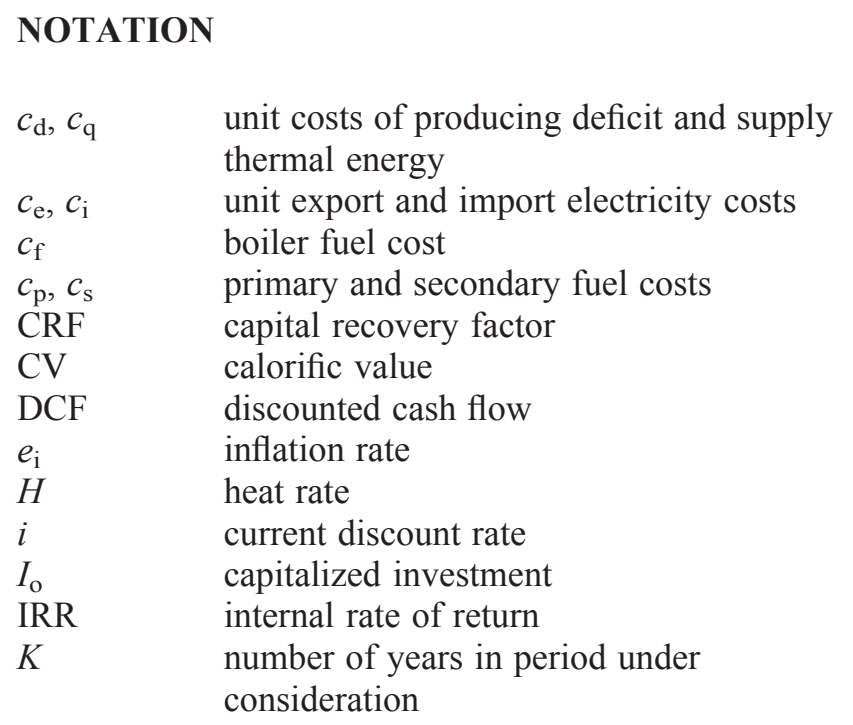

The MS was received on 25 February 1999 and was accepted after revision for publication on 11 January 2000.

*Corresponding author: Department of Mechanical Engineering, University of Durban-Westville, Private Bag X54001, Durban 4000, South Africa.

$L$
$m$
$n$
$\mathrm{NPV}$
$P$
$\mathrm{PWF}$
$Q$
$T$
$\mu$

\section{Subscripts}

d debt

e equity

$k \quad$ year under consideration

$l \quad$ load curve type (season) under consideration

p primary

s secondary

$t \quad$ time period under consideration 


\section{INTRODUCTION}

The total energy concept has been practised in industry for decades. The objective is to utilize to the fullest the heat energy available to a system at the various temperature levels at which it occurs to produce useful energy, with a minimum of waste energy. The energy crises of the 1970s increased awareness of the need for greater energy conservation methods and efficiency of use, if continued economic growth and improved quality of life are to be maintained. The rapid depletion of fossil energy resources and the wanton degradation of the environment have brought a new dimension into the energy debate. One option of energy total use that is increasingly being adopted is to recover as useful energy some of the waste energy leaving a power plant, as practised in combined cycle and combined heat and power (CHP) plants.

Until not too long ago, it was required of the engineer to design the most advanced energy system for a given duty, without giving due regard to the economic implications of the design over the lifetime of the system. Much attention was given to technical details and cost considerations over the lifetime of the plant were left to those versed in financial management. It was usual to seek the optimum thermodynamic performance that resulted in the highest thermal efficiency possible using state-of-the-art technology. An indication of the size of the plant, and therefore of its cost, was obtained from the designed specific output. Present-day supply side economics demands that competing energy systems must as well contribute to the efficient use of financial resources. The long-term nature of energy plant investment makes it imperative that the correct decision in choice be made as the effects of the investment decision remain with the organization for the lifetime of the plant. A multidisciplinary approach is required therefore to tackle effectively future energy problems, and a designer should be able to assess the economic impact of his designs.

With combined cycle plants, the most efficient energy system for a given duty requires the highest capital outlay, when state-of-the-art technology is used. This alternative incurs the largest capital recovery cost and, probably, the lowest fuel or energy cost, but not necessarily the lowest operation, maintenance and miscellaneous costs. In cases where an increment in plant efficiency leads to a reduction in production costs, the increase in capital outlay required to attain the increment in efficiency may not be justifiable, when the efficient use of capital is taken into consideration. By carrying out life cycle costs analysis a designer can determine the most economical alternative for a given duty.

Various techniques have been proposed to address the economic selection of combined energy plants, from an engineering viewpoint. One thing the majority have in common is that they do not consider detailed load profiles, but rather they obtain the yearly load output from a knowledge of the peak load and load factor or of the maximum load and the capacity factor. For plants with significant variations in output, this could lead to a significant error in the computed fuel cost, which is the single largest cost item in the revenue requirement. However, the methods do give useful results from which meaningful conclusions can be drawn and on which the decision to invest in a particular system rather than in an alternative can be based.

The true economic potential of an investment can be assessed only by carrying out a complete and detailed economic analysis of the alternatives. This exercise could be costly and time consuming. Given the energy and cost savings potential of combined energy plants, a considerable number of organizations in industry and other economic sectors have invested hugely in such energy systems worldwide, and the trend is growing. It is necessary that a detailed economic analysis of competing designs be carried out by a prospective bidder to ensure that he or she remains competitive, on the one hand, and on the other by the prospective investor to ascertain that financial resources are utilized most effectively.

A computer-based economic model was developed for appraising alternative gas-steam turbine combined cycle and CHP (cogeneration) investment proposals. A detailed year-by-year life cycle costs analysis is carried out to quantify the economic indicator, which is either the net present value, (NPV) or the internal rate of return (IRR). Also, a proposal can be qualified against an alternative when both alternatives give acceptable internal rates of return. The model is flexible enough to include other types of energy system in an appraisal. The methodology adopted departs from the usual by considering detailed load profiles and seasonal variations of load and fuel and energy costs.

\section{THE ECONOMIC MODEL}

In attempting to judge the attractiveness of an energy investment proposal, an engineering economy study should be carried out. The question to be answered by this exercise is whether the proposed capital investment and its associated expenditures can be recovered over time, in addition to a return on capital that is sufficiently attractive in view of the risks involved and the alternative uses of limited funds. To achieve this an economic indicator is defined and quantified by the study.

The various methods for appraising an engineering investment proposal can be found in standard texts on engineering economy, such as those by Grant et al. [1] and Steiner [2]. Mackay [3] summarized the main methods, giving illustrations. Discounted cash flow (DCF) techniques are commonly used when a detailed and accurate economic analysis is required, as they take 
into account the importance of the time value of money. The particular DCF technique applied depends on whether or not revenue and/or capital charges are taken into consideration. For example, when, as in electricity supply, there is a demand and the question of not supplying that demand does not arise, revenue is common to all alternatives and can be excluded from the analysis by considering annual costs only, which may or may not include fixed capital charges. In the generalized procedure presented here, revenue and capital charges are taken into consideration.

The two yardsticks used in the economic model for deciding between alternatives are the net present value and the internal rate of return. When the minimum attractive rate of return (interest rate) is given the net present value is obtained, otherwise, the internal rate of return (interest rate) is calculated. When the NPV is the economic indicator, the proposal is economically viable if the NPV is equal to or greater than zero, and when the NPVs of two alternatives are compared the one with the higher NPV is the more attractive. An investment proposal is also economically viable if the internal rate of return is greater than the minimum acceptable rate of return on capital. When two alternatives have internal rates of return that are acceptable, the incremental rate of return is compared against the incremental capital cost to determine which proposal is the more attractive. In DCF analysis the interest rate is called the discount rate. The latter term is used in the text, hereafter.

\subsection{Financial mathematics}

With regard to the flow of cash, the period of the economy study is assumed to start in the year a contractor is awarded the tender to install the plant and to end in the year the plant is taken out of service permanently. Thus, the period under study is divided into two distinct phases, the construction (or erection) and the operational phases (Fig. 1). The line of demarcation is taken as the date at which the plant is commissioned to enter service. Discounting, or present valuing, converts all cash amounts to equivalent amounts at a reference date called 'the present'. A suitable date commonly assumed is the date of commissioning, i.e. the year in which the useful life of the equipment begins.

If $\mathrm{CF}_{k}$ is a cash flow in year $k, k$ being the number of years from the present, then the present value of the cash flow, $\mathrm{PV}_{k}$, is obtained by multiplying the cash flow by the present worth factor for the year, i.e.

$$
\mathrm{PV}_{k}=\mathrm{CF}_{k} \mathrm{PWF}_{k}
$$

where

$$
\mathrm{PWF}_{k}=\frac{1}{(1+i)^{k}}
$$

$i$ is the inflation-adjusted discount rate reflecting the current money market. An inflation-adjusted interest rate is obtained from the expression

$$
i=\left[\left(1+i_{\mathrm{c}}\right)\left(1+e_{\mathrm{i}}\right)\right]-1
$$

when the interest rate in the absence of inflation, $i_{\mathrm{c}}$, and the inflation rate, $e_{\mathrm{i}}$, are known [4]. If the cash flow, $\mathrm{CF}_{k}$, were the net cash flow (receipts minus disbursements), then the net present value of the cash flows would be obtained by summing the present values over the period under consideration ( $K$ years), i.e.

$$
\mathrm{NPV}=\sum_{k=1}^{K} \mathrm{PV}_{k}
$$

In any particular year, cash receipts and disbursements occur at any time as the transaction warrants. Discounting the cash flows to the reference date whenever they occurred would lead to a cumbersome and tedious analysis. It is assumed that all cash flows are timed to occur on the last day of the year in which the transaction took place. Thus, the net cash flow, which occurs at the end of the year, as depicted in Fig. 1, represents all monetary transactions that occur during a year. The

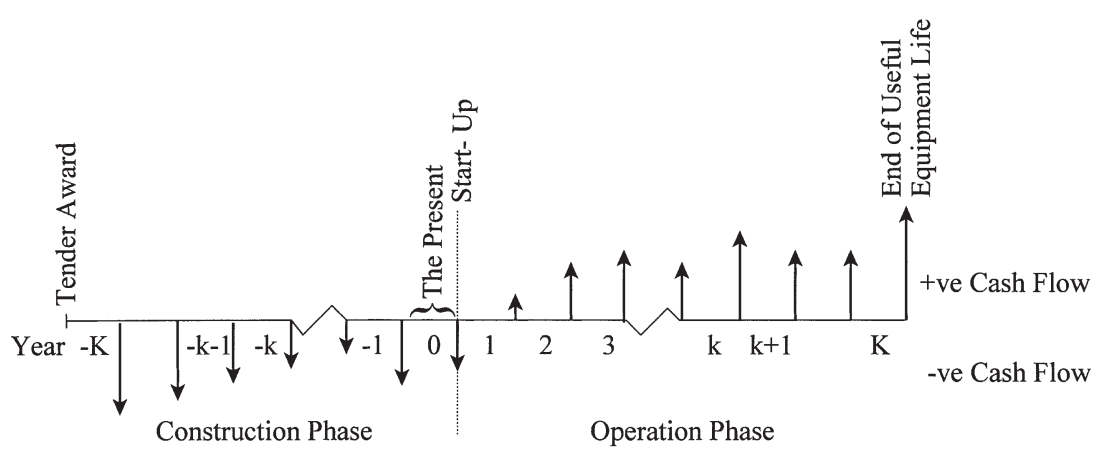

Fig. 1 Energy system investment life cycle 
yearly net cash flows may be irregular but can be levellized to give a uniform series of annual net cash flows. The levellized net present value, $\overline{\mathrm{NPV}}$, is obtained by multiplying the net present value by the capital recovery factor, i.e.

$$
\overline{\mathrm{NPV}}=\mathrm{NPV} \times \mathrm{CRF}
$$

where the capital recovery factor, $\mathrm{CRF}$, is given by

$$
\mathrm{CRF}=i /\left[1-1 /(1+i)^{K}\right]
$$

The net cash flow is the sum of a number of cash flows. The yearly projections of cash flow for each cost item must be known for the costs analysis to be carried out. It is difficult to predict cash flows beyond three or four years, but, if constant annual inflation and escalation rates are assumed, the yearly cash flows can be predicted to the same degree of accuracy for all alternatives. With certain cost items, the cash flows for the second and subsequent years are calculated from the cash flow of the first year when the apparent annual escalation rate is known. If $e_{\mathrm{r}}$ is the real annual escalation rate, the apparent annual escalation rate, $e_{\mathrm{a}}$, is given by the expression

$$
e_{\mathrm{a}}=\left[\left(1+e_{\mathrm{r}}\right)\left(1+e_{\mathrm{i}}\right)\right]-1
$$

Care should be exercised when applying the annual apparent escalation rate to cash flows timed to occur at the end of a year, as escalation rates are applied to prices quoted at the beginning of the year. To obtain the cash flow for year $k$ the factor $\left(1+e_{\mathrm{a}}\right)^{k-1}$ is applied to the cash flow for year 1 .

During the construction phase capital costs are incurred. These do not necessarily have to be regarded as lump sum payments; they can be assumed to be spread over the construction period according to the expected incidence of expenditure. During the operational phase revenue and/or savings are accrued and expenses incurred.

In putting it all together, an attempt is usually made to write a mathematical expression representing a particular situation. Spreadsheets are used in practice to carry out the analysis step by step. However, a computer program provides ease of computation as it can be structured to perform the duties of a spreadsheet and to represent the relevant mathematical expression. PEACES (program for the economic analysis of combined energy systems) is no exception. PEACES was developed to run on personal computers operating on DOS.

\subsection{Capital investment}

In any industrial economic activity expenses are incurred in the running of an operation which produces one or more outputs from which revenue could be earned or savings made. The investment must first be made before the plant can start operation. In energy investment projects such as power plants for electrical power generation, the construction phase may last for a number of years during which a series of payments are made which make up the invested capital. Capital is assumed to be raised from debt and equity funds, and the total capital invested is greater than the sum total of the payments made, owing to the time value of money.

If $I_{j k}$ is the capital invested in year $k$ from equity $(j=1)$ or debt $(j=2)$ funds and $\mathrm{PWF}_{j k}$ is the corresponding present worth factor for the year at the appropriate discount rate $i_{j}$, then the present value of the capital payment is $I_{\mathrm{o}_{j k}}=I_{j k} \mathrm{PWF}_{j k}$, where the present worth factor $\mathrm{PWF}_{j k}=1 /\left(1+i_{j}\right)^{k} \cdot i_{j}$ is the inflationadjusted cost of equity or debt capital. $k$ could be negative depending on the choice of the present, and when this is the case the present worth factor equals the compound amount factor. Taking into consideration price escalation during construction, the present worth factor is multiplied by $\left(1+e_{\mathrm{r}}\right)^{k}$ to give an adjustment factor $A_{j k}$. The net present value, $I_{\mathrm{o}}$, of capital invested from equity or debt funds during the construction period is

$$
I_{\mathrm{o}_{j}}=\sum_{k=1}^{K} I_{\mathrm{o}_{k}}=\sum_{k=1}^{K} I_{j_{k}} A_{j_{k}}
$$

and the net present value of the total capital invested is

$$
I_{\mathrm{o}}=\sum_{j=1}^{2} I_{\mathrm{o}_{j}}
$$

This appears as depreciation in the books of the organization and must be recovered over the lifetime of the plant, in addition to an attractive return on equity capital, $i_{1}, I_{\mathrm{o}}$ can be levellized to obtain equivalent uniform annual capital payments. The levellized sum is

$$
I_{\mathrm{o}}=I_{\mathrm{o}} \mathrm{CRF}
$$

where CRF is obtained from equation (6), but with $K$ being the construction time and $i$ the effective discount rate.

The effective discount rate used in discounting cash flows is the weighted cost of capital, defined as

$$
i=i_{\mathrm{e}} \alpha_{\mathrm{e}}+i_{\mathrm{d}} \alpha_{\mathrm{d}}
$$

where $i_{\mathrm{e}}$ and $\alpha_{\mathrm{e}}$ are the rate of return on and fraction of equity capital respectively and $i_{\mathrm{d}}$ and $\alpha_{\mathrm{d}}$ are the corresponding values for debt capital. An alternative method for arriving at the total capital invested, $I_{\mathrm{o}}$, is to apply the inflation-adjusted effective discount rate obtained from equation (11) to the total capital (debt 
plus equity) invested yearly. Once the investment is made and the plant goes into service the user must collect adequate revenue and/or make adequate savings to meet certain yearly financial obligations in addition to an attractive return on the investment.

\subsection{Evaluation of the economic performance index}

The purpose of an economy study is to quantify a performance index that gives an indication of the attractiveness of a proposed investment. This can be accomplished by developing an economic model that accounts for all cash flows occurring during the lifetime of the project.

The cash flow structure applicable yearly over the operational phase of the plant is shown in Fig. 2. Expenses, referred to as operational costs, OC, are deducted from the receipts, REV, to obtain the income before tax, GI. An operating expense can be conveniently identified as belonging to one of the following cost groups: fuel, operation and maintenance, debt interest and miscellaneous. It may be convenient to lump one or more groups together, for ease of computation. Debt interest, as shown, could be tax deductible; when this is not the case the operating costs are reduced with the result that taxes are increased. Next, depreciation, $\mathrm{DEP}_{\mathrm{T}}$, and the allowable tax deductions, $\mathrm{AD}$, are deducted from the net income before tax to obtain the taxable income, TI, to which the income tax rate, $r$, is applied to yield the income tax payable. Depreciation as shown is not the book depreciation but that allowed by the tax code for tax purposes. Income after tax is obtained by deducting the income tax, TAX, from the taxable income, and on adding to it the depreciation and allowable deductions the net income, NI, is obtained, which is separated into capital charge, CR, and the return on investment (interest on equity), ROI. The

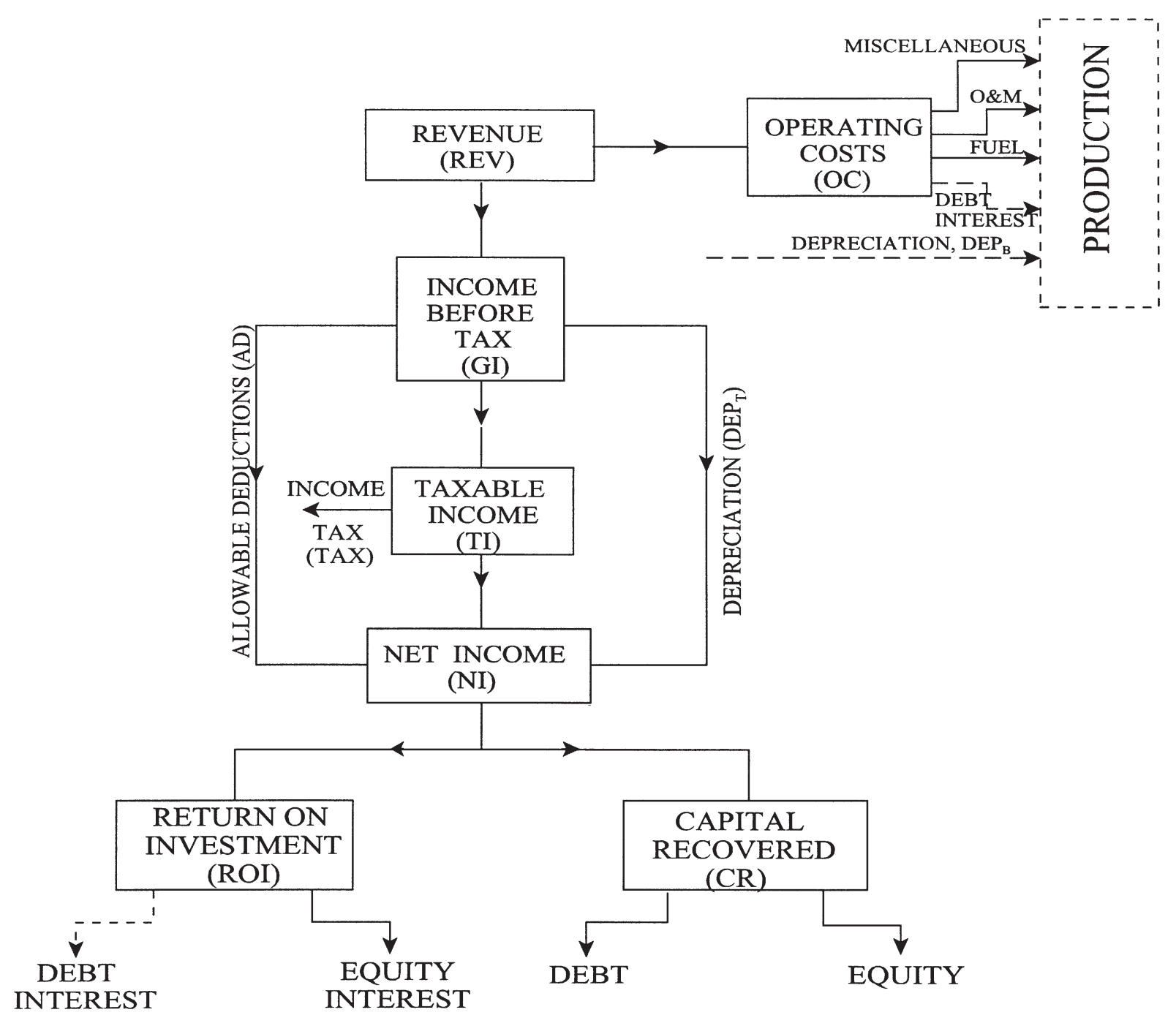

Fig. 2 The economic model 
following equations are applicable:

$$
\begin{aligned}
& \mathrm{GI}=\mathrm{REV}-\mathrm{OC} \\
& \mathrm{TI}=\mathrm{GI}-\mathrm{DEP}_{\mathrm{T}}-\mathrm{AD} \\
& \mathrm{TAX}=r \mathrm{TI} \\
& \mathrm{NI}=\mathrm{DEP}_{\mathrm{T}}+\mathrm{AD}+(1-r) \mathrm{TI} \\
& \mathrm{ROI}=\mathrm{NI}-\mathrm{CR}
\end{aligned}
$$

The capital charge is the sum of equity and debt payments and could be viewed as having a magnitude similar to that of book depreciation. Note that in any one year the book depreciation is positive but the tax depreciation could be zero, if the tax life of the investment is less than the equipment life, which is normally the case for long-term projects. The rate of return on the investment is obtained by dividing the return on investment by the equity capital. When debt interest is not tax deductible it should be subtracted from the value of ROI obtained from the expression above to obtain the actual return on investment.

The financial obligations associated with the invested capital and with the operation of the plant that the investor must meet yearly are called revenue requirement, RR, collectively. The revenue requirement is defined as

$$
\mathrm{RR}=\mathrm{OC}+\mathrm{DEP}_{\mathrm{B}}+\mathrm{TAX}+\mathrm{ROI}
$$

where $\mathrm{DEP}_{\mathrm{B}}$ is the book depreciation. A proposal is economically viable if the net present value of the net cash flow or its levellized sum is greater than or equal to zero. The internal rate of return is the discount rate at which the net present value of the cash flows is zero. Therefore, by setting equation (4) or (5) equal to zero and solving simultaneously with equation (11), the discount rate $i_{\mathrm{e}}$ is obtained.

\section{THE OPERATION PHASE}

The receipts obtained from the use of the plant goes mainly to meeting financial obligations associated with the decision to invest in and to own the plant. These payments are related directly either to the investment, and are therefore independent of the yearly plant output, or to the operation of the plant.

\subsection{Revenue requirements}

\subsubsection{Depreciation}

Depreciation should be looked at from two viewpoints, taxes and pricing of output. At start-up, the book value of the plant is equal to the capitalized investment, i.e. the invested capital plus all interest charges. The plant depreciates in value yearly and may or may not have a salvage value at the end of its useful life. For tax purposes, depreciation, $\mathrm{DEP}_{\mathrm{T}}$, is calculated according to the applicable depreciation accounting formula. For pricing purposes, depreciation, $\mathrm{DEP}_{\mathrm{B}}$, is the difference in book values at the beginning and end of the year. The yearly book depreciation charge may be given for the depreciation period applicable or can be calculated when the book value at the beginning of each year is given. When a straight line depreciation is applied, $\mathrm{DEP}_{\mathrm{B}}$ is obtained from the expression

$$
\mathrm{DEP}_{\mathrm{B}}=\frac{I_{\mathrm{o}}-S}{K}
$$

where $S$ is the salvage value of the plant.

\subsubsection{Debt interest}

Debt interest is the interest on debt owed at the beginning of a year. A provision can be made to retire at the end of a year a portion of the debt owed, when necessary. The debt owed at the beginning of a year is equal to that owed at the beginning of the previous year minus that retired at the end of the previous year. If $I_{\mathrm{O}_{\mathrm{d}}}$ is the debt portion of the capitalized investment, then the debt interest payable in year $k$ is

$$
D_{\text {int }_{\mathrm{k}}}=\left(I_{\mathrm{Od}}-\sum_{k=1}^{K} \mathrm{DR}_{k-1}\right) i_{\mathrm{d}}
$$

where DR is the debt retired in a year, with $\mathrm{DR}_{\mathrm{o}}$ taking a null value.

\subsubsection{Operation and maintenance}

The operation and maintenance (O\&M) charge comprises a fixed and a variable charge. The fixed charge, $C_{\mathrm{f}}$ (in monetary units per year), does not depend on the output of the plant in a year, but rather it is set by considerations relating to the operation and maintenance of the plant, fixed by the decision to keep the plant in service. It is subject to inflation and price escalation. The variable charge varies in direct proportion to the yearly output. The constant of proportionality, $C_{\mathrm{v}}$, is given in monetary units per kilowatt hour. The total output for the year is required to evaluate the variable operation and maintenance charge. The total operation and maintenance cost, $C_{\mathrm{O \& M}}$, is therefore

$$
C_{\mathrm{O} \& \mathrm{M}}=C_{\mathrm{f} \mathrm{O \& M}}+C_{\mathrm{v} \text { O\&M}} W
$$

where $W$ is the total number of kilowatt hours of energy produced in a year. 


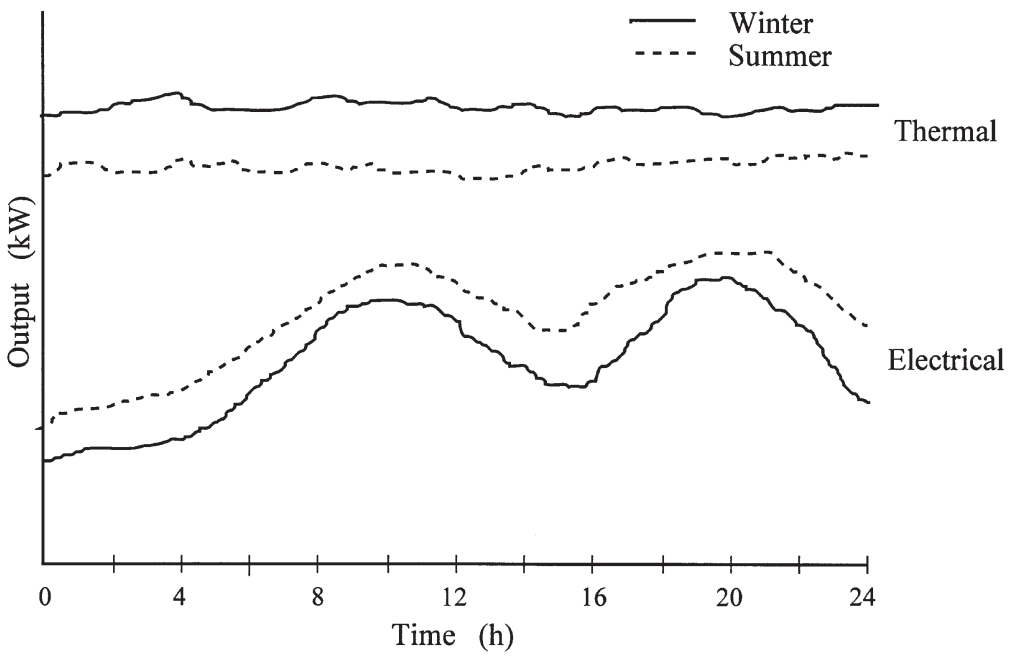

Fig. 3 Seasonal load profiles

The expense allocated to miscellaneous items is also composed of fixed and variable portions. For computational purposes this charge is lumped together with the operation and maintenance charge given above.

\section{1 .4 Fuel}

The amount of fuel consumed, and thus the fuel charge, depends on the annual output of the plant. To be able to evaluate the fuel charge, the supply load curve must be given and the heat rate of the plant as a function of load must be known. Depending on the duty to which the plant is put the supply and the demand loads may or may not coincide.

For a detailed and accurate analysis, daily load curves covering entire $24 \mathrm{~h}$ periods are required. Such curves are shown in Fig. 3. The matter is complicated by the fact that the load curves may be seasonal, and, when the price(s) of the fuel(s) used and the tariff on the load sold or bought in vary with season and/or with the time of day, a further complication is introduced.

Let the daily load curves be denoted by $l(l=1,2$, $\ldots, L)$, where $L$ is the number of different load curves (seasons) applicable in a year, and let the number of days in a year for which load curve type $l$ applies be $n_{l}$. Each load curve is divided into a finite number of time periods $t\left(t=1,2, \ldots, T_{l}\right)$ chosen such that the supply and demand loads for the product, the $\operatorname{cost}(\mathrm{s})$ of the fuel(s) supplied and the tariffs on the product and byproduct sold and bought in do not vary significantly over the period (Fig. 4). Provision is made for firing fuel at a maximum of two different points in the plant. The fuels may or may not be the same. The masses of the fuels consumed are obtained from the performance curves of the plant (Fig. 5).

Consider a plant producing electricity. For curve $l$, Fig.
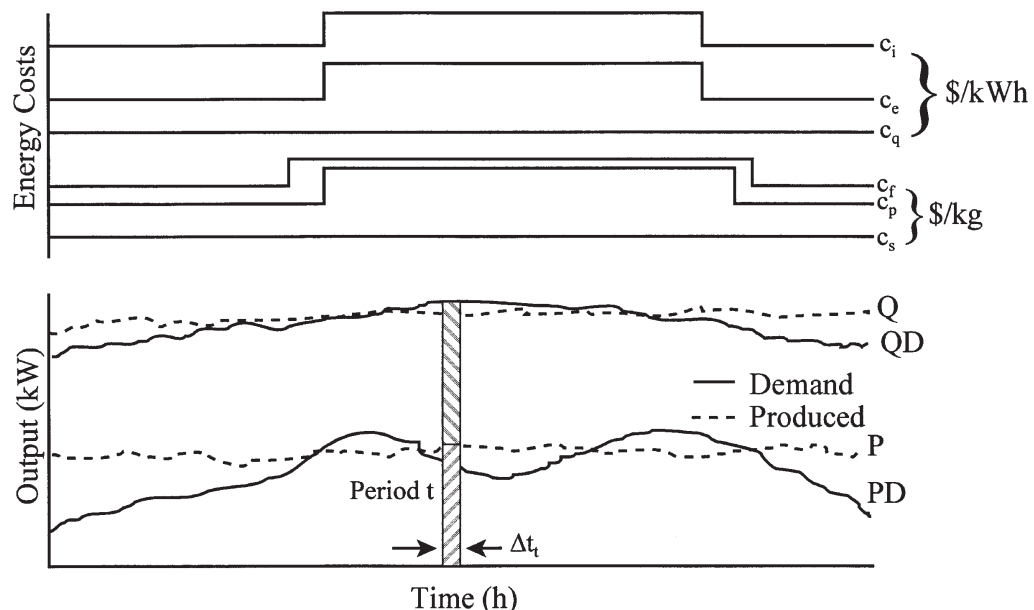

Fig. 4 Representative energy curves for a season 


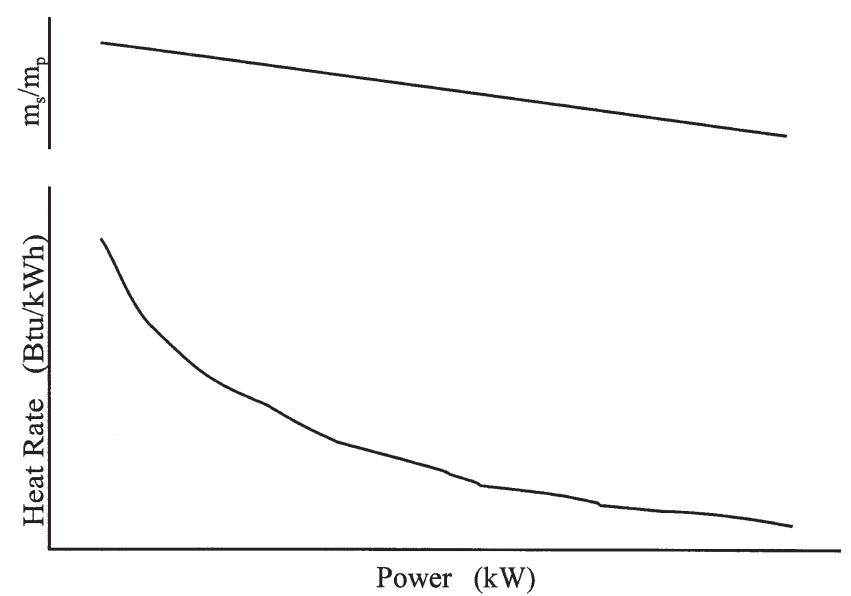

Fig. 5 Plant performance curves

4 , the sum total of fuel energy input during period $t$ in unit time, $E_{l, t}$, is

$$
E_{l, t}=\left(E_{\mathrm{p}}+E_{\mathrm{s}}\right)_{l, t}=P_{l, t} H_{l, t}
$$

where $P_{l, t}$ is the power output, constant over period $t, H_{l, t}$ is the corresponding heat rate (Fig. 5) based on the energy input of the primary fuel and the suffixes $\mathrm{p}$ and $\mathrm{s}$ denote primary and secondary fuels. The mass of the primary fuel burnt in unit time is

$$
\dot{m}_{\mathrm{p}_{l, t}}=\frac{P_{l, t} H_{l, t}}{\mathrm{CV}_{\mathrm{p}}+\mu_{l, t} \mathrm{CV}_{\mathrm{s}}}
$$

where $\mathrm{CV}$ is calorific value and $\mu$, the mass ratio $m_{\mathrm{s}} / m_{\mathrm{p}}$, is a function of $l$ and $t$. Over time $\Delta t_{l, t}$, the total primary fuel burnt is

$$
m_{\mathrm{p}_{l, t}}=\dot{m}_{\mathrm{p}_{l, t}} \Delta t_{l, t}=\frac{P_{l, t} H_{l, t} \Delta t_{l, t}}{\mathrm{CV}_{\mathrm{p}}+\mu_{l, t} \mathrm{CV}_{\mathrm{s}}}
$$

and the total secondary fuel burnt is

$$
m_{\mathrm{s} l, t}=\mu_{l, t} m_{\mathrm{p}_{l, t}}
$$

for an output energy $P_{l, t} \Delta t_{l, t}$. The total primary or secondary fuel consumed in one day when load of type $l$ applies can be found by summing equation (19) or (20) over the time periods, $T_{l}$. However, it is the cost of the fuel consumed that is required and since fuel cost may vary with the time of the day it is necessary to multiply equations (19) and (20) by fuel cost before the summation is taken. If the costs of the fuels are $c_{\mathrm{p}_{l, t}}$ and $c_{\mathrm{s} l, t}$, the cost of the primary fuel consumed in a day is

$$
f_{\mathrm{p}_{l, t}}=\sum_{t=1}^{T_{l}} m_{\mathrm{p}_{l, t}} c_{\mathrm{p}_{l, t}}=\sum_{t=1}^{T_{l}} \frac{P_{l, t} H_{l, t} \Delta t_{l, t} c_{\mathrm{p}_{l, t}}}{\mathrm{CV}_{\mathrm{p}}+\mu_{l, t} \mathrm{CV}_{\mathrm{s}}}
$$

and that of the secondary fuel is

$$
f_{\mathrm{s}_{t}}=\sum_{t=1}^{T_{l}} m_{\mathrm{s}_{l, t}} c_{\mathrm{s}_{l, t}}=\sum_{t=1}^{T_{l}} \frac{\mu_{l, t} P_{l, t} H_{l, t} \Delta t_{l, t} c_{\mathrm{s}_{l, t}}}{\mathrm{CV}_{\mathrm{p}}+\mu_{l, t} \mathrm{CV}_{\mathrm{s}}}
$$

In one year, the total fuel cost for load type $l, F_{l}$, is given by

$$
F_{l}=n_{l}\left(f_{\mathrm{p}_{l}}+f_{\mathrm{s}_{l}}\right)
$$

The total cost of fuel consumed by the plant in one year, $F$, is thus

$$
F=\sum_{l=1}^{L} F_{l}=\sum_{l=1}^{L} n_{l} \sum_{t=1}^{T_{l}} \frac{\left(c_{\mathrm{p}_{l, t}}+\mu_{l, t} c_{\mathrm{s}}\right) P_{l, t} H_{l, t}}{\left(\mathrm{CV}_{\mathrm{p}}+\mu_{l, t} \mathrm{CV}_{\mathrm{s}}\right) \Delta t_{l, t}}
$$

and the total electrical energy is

$$
P=\sum_{l=1}^{L} n_{l} \sum_{t=1}^{T_{l}} P_{l, t} \Delta t_{l, t}
$$

Consider now heat produced in a heat-only boiler. If $\dot{Q}_{l, t}$ is the rate at which the boiler produces heat during period $(l, t)$, the heat produced during this period is $Q_{l, t}=\dot{Q}_{l, t} \Delta t_{l, t}$, and the mass of fuel consumed is $m_{\mathrm{B}}, t=Q_{l, t} \mathrm{CV} \eta_{\mathrm{B}}$, where $\mathrm{CV}$ is the calorific value of the fuel and $\eta_{\mathrm{B}}$ the boiler efficiency, assumed constant although in general it depends on the load. The cost of this fuel is $m_{\mathrm{B}_{l, t}} c_{\mathrm{f}_{l, t}}$, where $c_{\mathrm{f}_{l, t}}$ is the cost of the fuel per kg, and the heat produced in one day is $Q_{i}=\sum_{t=1}^{T_{l}} Q_{l, t}$, at a cost $\sum_{t=1}^{T_{l}} m_{\mathrm{B}_{l, t}} c_{\mathrm{f}}$. . So the amount of fuel consumed in one year when load type $l$ applies is $n_{l} Q_{l}$, at a cost $n_{l} \sum_{t=1}^{T_{l}} m_{\mathrm{B}_{l, t}} c_{\mathrm{f}}$. . The total heat produced in one year is therefore

$$
Q=\sum_{l=1}^{L} n_{l} \sum_{t=1}^{T_{l}} \dot{Q}_{l, t} \Delta t_{l, t}
$$

at a cost

$$
F_{\mathrm{B}}=\sum_{l=1}^{L} n_{l} \sum_{t=1}^{T_{l}} m_{\mathrm{B}_{l, t}} c_{\mathrm{f}_{l, t}}
$$

Depending on the type of plant, it may be necessary to add $F_{\mathrm{B}}$ to $F$ to obtain the annual fuel cost for the plant.

\subsubsection{Income tax}

Income tax comprises state income tax and local tax, and the tax rate reflects the combined effect. The income tax payable in a year is obtained from the expression

$$
\mathrm{TAX}=r \mathrm{TI}
$$


where the taxable income TI is given by

$$
\mathrm{TI}=\mathrm{REV}-\mathrm{OC}-\mathrm{DEP}_{\mathrm{T}}-\mathrm{AD}
$$

The income tax rate may increase or decrease over the lifetime of the project depending on the economic policies of the government of the day and also on the economic performance of the state. It is reasonable to assume that the rate will remain constant throughout the lifetime of the investment.

\subsubsection{Allowable deductions}

The allowable deductions are the sum total of all quantities, such as investment tax credit, allowances, etc., which are tax deductible under the income tax laws, i.e. they are deducted from the income before tax in the process of obtaining the taxable income. Their net effect is to reduce income tax. These could be made up of a fixed amount and an amount relative to the net income before tax, i.e.

$$
\mathrm{AD}=\mathrm{AD}_{\mathrm{f}}+(\mathrm{GI}-A) a
$$

where $A$ is a base amount and $a$ is a fraction. In other words, the relative amount is a certain percentage of the before-tax cash flow exceeding a certain amount, and so would be set equal to zero if negative.

\subsubsection{Return on investment}

The return on investment is a result of the calculations. It is obtained from equation (13) by setting revenue requirement equal to revenue.

\subsection{Revenue}

The receipts from the use of plant output(s) are revenue earned from the sale of the output(s), savings made by displacing purchased power and heat which would have been produced in a stand-alone boiler. With cogeneration plants, the heat output is usually used on site and not exported, except in cases of district heating. Additional power may be bought in depending on the business interests of the owner, who may be a utility company, an independent power producer or an industrial user. When this is the case, the cost of the power bought in can be considered to be an operating expense that reduces revenue earned. The revenue earned, savings made and expenses incurred for additional purchased power are obtained from an analysis of the supply and demand load curves.

Figure 4 showed the supply and demand load curves for power and heat for a generalized situation. There is no heat output in a pure combined cycle plant, and, when the business interest of the investor is only to generate energy for sale, the supply and demand load curves are usually coincident. In the case where the plant is expected to provide power at the site to displace purchased energy, several scenarios may arise as excess power may be available for export, or there may be a deficit of power, which results in power being imported. The cost of reserve capacity and the availability of the plant should be taken into consideration in the analysis. As PEACES does not yet have such a capability, these are avoided in the analysis by assuming that a large grid is available from and to which power can be bought and sold as necessary. The analysis is thus most applicable to industrial energy generation.

Firstly, consider the electrical energy produced by the plant. If over period $(l, t)$ the demand load is $\mathrm{PD}_{l, t}$, the excess energy is $\Delta P_{l, t}=\left(P_{l, t}-\mathrm{PD}_{l, t}\right) \Delta t_{l, t}$. When $\Delta P_{l, t}$ is positive the excess energy is sold at an export price $c_{\mathrm{e}_{l, t}}$ and revenue is earned, and when it is negative the deficit is bought at an import price of $c_{\mathrm{i}_{l, t}}$ and expenses are incurred. In either case, the portion of energy produced which meets the demand load results in a saving at the unit import price. $\Delta P_{l, t}$ is equal to zero when the demand and supply loads coincide. There is the rare case where all the energy produced by the plant is exported and that required at the site is purchased. The switched-off mode is accounted for in the load curves.

For period $(l, t)$, the saving made from displacing load $\mathrm{PD}_{l, t} \Delta t_{l, t}$ that would otherwise have been bought is $\mathrm{PD}_{l, t}$ $\Delta t_{l, t} c_{\mathrm{i}, t, t}$, and the revenue earned from exporting the excess load $\Delta P_{l, t}$ is $\Delta P_{l, t} c_{\mathrm{e} l, t}$. When $\Delta P_{l, t}$ is negative a saving $P_{l, t} \Delta t_{l, t} c_{\mathrm{i} l, t}$ is made by producing load that would have been bought and an expense $\Delta P_{l, t} c_{\mathrm{l} l, t}$ is incurred in purchasing the deficit energy. So the total revenue, $R_{\mathrm{p} l, t}$ received for the period is

$$
R_{\mathrm{p}_{l, t}}= \begin{cases}\left(P_{l, t} \Delta t_{l, t}+\Delta P_{l, t}\right) c_{\mathrm{i}_{l, t}}, & \Delta P_{l, t} \leqslant 0 \\ P_{l, t} \Delta t_{l, t} c_{\mathrm{i}_{l, t}}+\Delta P_{l, t} c_{\mathrm{e}}, & \Delta P_{l, t} \geqslant 0\end{cases}
$$

Now consider the heat produced by the plant. It is very unlikely that revenue can be earned from excess heat produced, and when more heat is required than produced the deficit energy must be generated in a heat-only boiler, as it is very unlikely that it can be bought. The normal assumption is made that the cost of the heat produced in a combined heat and power plant is the cost of generating the heat separately in a heat-only boiler [5].

If over the same period $(l, t)$ the cost of producing unit thermal energy is $c_{\mathrm{q}_{l, t}}$, the cost of the heat energy produced by the CHP plant during this period is $\dot{Q}_{l, t} \Delta t_{l, t} c_{\mathrm{q}_{l, t}}$, when there a surplus of heat, and $\dot{Q} D_{l, t} \Delta t_{l, t} c_{\mathrm{q}_{l, t}}$, when there is a deficit. This amount of money is saved by not producing the heat in a heat-only boiler and receipts are increased. If the deficit heat energy in this period is $\Delta Q_{l, t}=\left(\dot{Q}_{l, t}-\dot{Q} D_{l, t}\right) \Delta t_{l, t}$, and the unit cost of producing this energy is $c_{\mathrm{d}_{l, t}}$, then the cost of producing the deficit energy is $\Delta Q_{l, t} c_{\mathrm{d} l, t}$. This is an expense that reduces revenue. So the total savings made 
over the period by producing all or part of the thermal energy is

$$
R_{\mathrm{q}_{l, t}}=\left\{\begin{array}{cc}
\dot{Q} D_{l, t} \Delta t_{l, t} c_{\mathrm{q}_{l, t}}+\Delta Q_{l, t} c_{\mathrm{d}_{l, t}}, & \Delta Q_{l, t} \leqslant 0 \\
\dot{Q}_{l, t} \Delta t_{l, t} c_{\mathrm{q}_{l, t}}+\Delta Q_{l, t} c_{\mathrm{d}_{l, t}}, & \Delta Q_{l, t} \geqslant 0
\end{array}\right.
$$

This should be added to the revenue $R_{\mathrm{p} l, t}$ obtained above to obtain the total receipts for the use of the outputs of a cogeneration plant. So for a plant producing only electricity or heat, or a combination of both, the total receipts from the use and/or sale of the output(s) for any period $(l, t)$ is

$$
R_{l, t}=R_{\mathrm{p}_{l, t}}+R_{\mathrm{q}_{l, t}}
$$

In one day the total amount received for load type $l$ is $R_{l}=\sum_{t=1}^{T} R_{l, t}$ and in one year is $\mathrm{REV}_{l}=n_{l} R_{l}$. The total cash flow from revenue for one year is

$$
\mathrm{REV}=\sum_{l=1}^{L} \mathrm{REV}_{l}
$$

When the heat produced is sold off as for district heating plants, the unit sale price replaces $c_{\mathrm{q} l, t}$ in equation (32). The unit costs $c_{\mathrm{i} l, t}$ and $c_{\mathrm{e} l, t}$ are usually known but $c_{\mathrm{q} l, t}$ and $c_{\mathrm{d} l, t}$ must be determined. The costs of producing unit electrical and unit thermal energies are considered next.

\section{COSTING THE OUTPUTS}

In situations where the generation of electrical power for use on site is being considered, the cost of generating electricity, also known as busbar energy cost, may be compared with the purchased price of electricity to determine if the venture is economical. As shown in Fig. 2 , production costs comprise fuel, operation and maintenance, miscellaneous, debt interest and book depreciation. The last two make up the capital charge, $C$, and for computational purposes miscellaneous charges are lumped into operation and maintenance costs, OM.

Following the method of Horlock [5,6], the total production cost in year $k, Y_{k}$, is

$$
\mathrm{Y}_{k}=\mathrm{C}_{k}+\mathrm{OM}_{k}+\mathrm{F}_{k}
$$

where $F$ is fuel cost. If the plant produced only electrical energy, the unit cost of the energy produced in that year would be $c_{\mathrm{c}_{k}}=Y_{k} / P_{k}$, where $P_{k}$ is given by equation (25). The annual cost of electricity, $c_{\mathrm{c}}$, is obtained by use of equations (1), (4) and (5).

In the case of CHP, $Y_{k}$ is the cost of producing both electricity and heat in the plant. The cost of the electricity produced is obtained by deducting from $Y_{k}$ the cost of the heat produced. The procedure outlined above in the determination of $c_{\mathrm{c}}$ is followed to obtain the cost of producing heat in a heat-only boiler. The capital, operation and maintenance, and fuel costs for the boiler are all determined as explained in Section 3.1. Writing the cost of producing heat in a heat-only boiler as

$$
Y_{\mathrm{B}_{k}}=C_{\mathrm{B}_{k}}+\mathrm{OM}_{\mathrm{B}_{k}}+F_{\mathrm{B}_{k}}
$$

the unit cost is obtained by dividing $Y_{\mathrm{B}_{k}}$ by the total heat produced in the year, i.e. by equation (26). The quantities $c_{\mathrm{q} l, t}$ and $c_{\mathrm{d} l, t}$ can now be determined for the corresponding annual heat outputs, using the procedure outlined above for obtaining the annual cost of electricity produced in a power-only plant. The cost of producing the power in a cogeneration plant is therefore $Y_{k}-Y_{\mathrm{B}_{k}}$, and the unit cost calculated as above.

\section{CLOSURE}

\subsection{Multiple alternatives}

The challenger and defender methodology of decision analysis should be used to determine which alternative should be chosen when two or more alternatives are involved. As a rule, multiple alternatives are analysed incrementally. The alternatives are first ordered from lowest to highest first cost, $I_{\mathrm{o}}$, and when an alternative fails it disappears from the problem as no succeeding alternative is compared against a failed one. With certain economic indicators, such as the net present value, a comparison of individual values also determines which alternative should be chosen. When the internal rate of return is the performance parameter, multiple alternatives must be compared on an incremental basis because it may not be true that the alternative with the higher IRR is the more viable. Steiner [2] covers this aspect in detail.

In general, if the difference in net cash flow between two alternatives $\mathrm{A}$ and $\mathrm{B}$ is $\mathrm{CF}_{\mathrm{B}-\mathrm{A}}$, the incremental net present value, $\mathrm{NPV}_{\mathrm{B}-\mathrm{A}}$, is obtained from equations (1) and (4). It is assumed that the defender, alternative $\mathrm{A}$, is better than the existing situation. When the net present value is the economic criterion, the challenger, alternative $\mathrm{B}$, is chosen over alternative $\mathrm{A}$ if the incremental net present value is greater than or equal to zero. In this case, the incremental net present value is also the difference in individual net present values, i.e. $\mathrm{NPV}_{\mathrm{B}-\mathrm{A}}=\mathrm{NPV}_{\mathrm{B}}-\mathrm{NPV}_{\mathrm{A}}$. When the internal rate of return is the economic performance parameter, the discount rate $i$ that nullifies $\mathrm{NPV}_{\mathrm{B}-\mathrm{A}}$ is the incremental rate of return, and it must be greater than the minimum acceptable IRR for B to be chosen over A. No decision can be taken on any two alternatives when their 
individual IRRs are each greater than the minimum acceptable IRR, unless the incremental IRRs are found. Note that $I R R_{B-A} \neq I R R_{B}-I R R_{A}$. When more than two alternatives are involved the process of elimination yields, eventually, the most viable alternative.

\subsection{Sensitivity analysis}

A unique value for the net present value or the internal rate of return is obtained for a given set of input variables, such as capital cost, project life, etc. The NPV or the IRR may change when an input variable changes, and it is possible that a value of an input variable may be arrived at which reverses the decision on whether or not to invest in a project. A simultaneous change in two or more of the input variables could lead to a premature reversal of the decision.

An economic appraisal of any project proposal must include an analysis of the sensitivity of the output parameter to a change in the input variables. This will reveal the variables of major importance. Once these are known further investigations should be carried out to answer vital questions before the final decision is made. In difficult cases, it may be necessary to perform a stochastic analysis in addition. By perturbing the relevant data and re-running the computer program, data are generated that can be used to carry out sensitivity analyses.

\section{CONCLUSIONS}

A methodology has been presented for carrying out life cycle costs analysis of combined energy investment proposals. The economic model was developed for appraising gas/steam turbine plants but its generalised structure enables proposals involving other types of energy system to be included with ease. A computer program called PEACES was created based on the economic model developed and is capable of finding the net present value or the internal rate of return, which can ascertain whether an energy investment proposal for a given situation is economically viable. The effects of inflation, price escalation and taxes can be included in any analysis, and seasonal variations of loads and fuel prices can be taken into account. In cases where competing alternatives are to be assessed against each other, an incremental analysis can be carried out to find the best alternative. When sensitivity analysis is required before the final decision to invest in an alternative is taken, the program can be run appropriately to generate the required data.

\section{ACKNOWLEDGEMENTS}

Financial support for this work was provided by the Alexander von Humboldt Foundation and institutional support provided by the Institute of Steam and Gas Turbines, Aachen University of Technology.

\section{REFERENCES}

1 Grant, L. G., Ireson, W. G. and Leavenworth, R. S. Principles of Engineering Economy, 8th edition, 1990 (John Wiley, New York).

2 Steiner, H. M. Engineering Economic Principles, 2nd edition, 1996 (McGraw-Hill, Singapore).

3 Mckay, G. Economic appraisal of energy conversion projects. In Chemical Engineering Series.

$4 T_{A} G^{(i x}$-Technical Assessment Guide, Vol. 3, 1987 (Electric Power Research Institute, Palo Alto, California).

5 Horlock, J. H. Cogeneration: Combined Heat and Power, 1987 (Pergamon, Oxford).

6 Horlock, J. H. Combined Power Plants, 1992 (Pergamon, Oxford). 